\title{
PAPARAN KONTEN VISUAL PADA FEED INSTAGRAM KOPI TOKO DJAWA SELAMA PANDEMI COVID-19
}

\author{
Rizki Yantami Arumsari ${ }^{1}$, Yanuar Rahman ${ }^{2}$ dan Bijaksana Prabawa ${ }^{3}$ \\ ${ }_{1,2,3}$ Program Studi Desain Komunikasi Visual, Fakultas Industri Kreatif, Telkom University, \\ Jl. Telekomunikasi, Bandung, Jawa Barat, 40257 \\ rizkiyantami@telkomuniversity.ac.id; vidiyan@gmail.com; bijaksanaprabawa@telkomuniversity.ac.id
}

Received: 8 Maret 2021

Revised: 20 Agustus 2021

Accepted: 25 Agustus 2021

\begin{abstract}
Abstrak: Semenjak adanya pandemi COVID-19 yang melanda dunia, termasuk Indonesia, pemerintah menghimbau untuk tetap di rumah saja dan memberlakukan Pembatasan Sosial Berskala Besar (PSBB) yang membuat aktivitas jual beli menurun hingga para pemilik kafe harus menutup usahanya sementara bahkan selamanya. Kopi Toko Djawa merupakan kafe yang tidak pernah sepi pengunjung, namun karena harus mematuhi himbauan pemerintah, akhirnya mereka pun harus membuat aturan baru yakni pelanggan hanya bisa melakukan take away. Agar pelanggan tetap terikat dengan Kopi Toko Djawa walau secara online, pengelola Kopi Toko Djawa memanfaatkan peran media sosial Instagram dengan cara membuat konten visual yang dipublikasikan dalam bentuk post pada Instagram mereka. Konten visual yang disajikan berbentuk foto, poster ataupun foto yang dijadikan poster. Isi dari konten visual tersebut antara lain mengingatkan para pengikut akun Instagram untuk tetap di rumah saja juga menginformasikan produk yang dapat dinikmati untuk berkegiatan di rumah. Melalui metode observasi, wawancara, dan analisis visual, penelitian ini bermaksud untuk mencari tahu bagaimana konten visual tersebut berhubungan dengan online engagement yang indikatornya adalah jumlah like dan comment. Hasil dari penelitian ini menunjukkan bahwa konten visual pada media sosial Instagram Kopi Toko Djawa dapat meraih jumlah like dan comment yang besar yang berarti konten visual tersebut dapat membuat online engagement yang baik walaupun dimasa sulit saat terjadi pandemi.
\end{abstract}

Kata kunci: Instagram, konten visual, Kopi Toko Djawa, online engagement, pandemi COVID 19

Abstract: Since the COVID-19 pandemic hit the world, including Indonesia, the government
has urged people to stay home and impose Large-Scale Social Restrictions (PSBB) that
make buying and selling activities decrease until café owners have to close their businesses
temporarily even forever. Kopi Toko Djawa is a cafe that is never empty of visitors, but
because they have to obey the government's appeal, they finally have to make a new rule
that customers can only take away. To keep customers tied to Kopi Toko Djawa even
online, The Kopi Toko Djawa manager utilizes the role of Instagram social media by
creating visual content published in the form of posts on their Instagram. Visual content is 
presented in photos, posters, or photos that are used as posters. The range of the visual content, among others, reminds followers to stay at home alone also informs products that they can enjoy doing activities at home. This study intends to find out how visual content relates to online engagement whose indicator is the number of likes and comments, through observation methods, interviews, and visual analysis. This study showed that visual content on social media Instagram Kopi Toko Djawa could get many likes and comments, which means that visual content can make good online engagement even in difficult times during pandemics.

Keywords: Instagram, Kopi Toko Djawa, Online Engagement, Pandemic COVID 19, Visual Content

\section{PENDAHULUAN}

Pada awal tahun 2020 hampir seluruh negara di dunia dilanda pandemi COVID-19. Akibatnya, banyak bisnis kafe yang mengalami penurunan pendapatan karena harus berhenti beroperasi untuk sementara (Elvira, 2020). Hal ini dikarenakan adanya himbauan untuk tetap di rumah saja dan Pembatasan Sosial Berskala Besar (PSBB) yang membuat para pelaku bisnis kafe harus memutar otak dan berusaha agar tidak kehilangan konsumen apalagi disaat krisis seperti ini.

Beberapa strategi dan cara yang pelaku bisnis lakukan adalah dengan menjual makanan dan minuman yang dapat tetap dinikmati oleh pelanggan di rumah. Misalnya dengan cara pesan antar atau take away, yakni dipesan melalui aplikasi online. Selain itu mengubah kemasan menjadi lebih besar agar bisa dinikmati bersama-sama di rumah, seperti minuman yang dibuat dalam ukuran satu liter.

Media sosial merupakan sebuah platform interaktif yang memfasilitasi setiap penggunanya untuk berbagi informasi (Ersoy, 2019). Selain berbagi informasi, media sosial juga dapat digunakan sebagai wadah untuk melakukan bisnis sehingga membuat cara berbisnis pun berbeda dari sebelumnya (Rathore \& Ilavarasan, 2019). Melalui media sosial, para pebisnis menyadari bahwa pelanggan potensial dapat ditemukan melalui perantara media ini sehingga penjualan pun 
dapat meningkat. Salah satu media sosial yang paling banyak digunakan untuk berbisnis adalah Instagram, yakni media sosial yang digunakan sebagai alat komunikasi dengan keunggulan dan kekhususannya untuk berbagi gambar, sehingga mampu menjadikannya alat pemasaran yang efektif (Kurniawati, 2017).

Melalui peran media sosial Instagram, para pelaku bisnis menginformasikan cara tersebut dengan membuat visualisasi berita untuk dipublikasikan pada feed atau halaman utama Instagramnya. Tidak hanya menginformasikan produk, beberapa pelaku bisnis kafe juga tak jarang membuat publikasi visual berupa post mengenai COVID-19, seperti protokol kesehatan atau mengingatkan kepada para pengikut akun Instagram agar tetap di rumah saja.

Kopi Toko Djawa adalah kafe di Bandung yang menyediakan beragam macam kopi. Awalnya berada di Jalan Braga kemudian membuka cabang di Jalan Riau, Jalan Burangrang dan pada tahun 2019 akhir membuka cabang di Jalan Gandapura. Toko kopi ini tidak pernah sepi pengunjung bahkan banyak warga Jakarta yang datang ke Bandung hanya untuk mencoba kopi dari kafe kopi ini. Ramainya pengunjung ini yang membuat mereka berinisiatif untuk membuka cabang di Pondok Indah, Jakarta pada akhir tahun 2019. Kondisi seperti ini mengindikasikan betapa banyaknya jumlah konsumen yang datang ke Kopi Toko Djawa secara reguler, tetapi karena pandemi COVID-19 akhirnya para konsumen tidak bisa datang ke tempat kecuali hanya untuk take away. Hal ini membuat Kopi Toko Djawa memanfaatkan Instagram untuk dapat terus mengikat para konsumennya. Pengelola akun Instagram Kopi Toko Djawa mengemas berbagai informasi dalam bentuk post pada Instagram, yang berisi cara-cara untuk tetap bisa menikmati Kopi Toko Djawa, mengingatkan untuk tetap di rumah saja, serta menginformasikan produk baru untuk mendukung konsumen berkegiatan dari rumah saja. 
Jenis publikasi yang dibuat oleh Kopi Toko Djawa adalah konten-konten visual dalam bentuk foto, poster ataupun foto yang dijadikan poster. Publikasipublikasi yang dibuat dalam post instagram ini cukup banyak mendapatkan tanda 'suka' atau like, juga 'komentar' atau comment dari para pengikutnya. Like dan comment merupakan indikator yang digunakan untuk mengukur online engagement atau keterikatan dan keterlibatan pada media sosial (Pendle, 2020). Adapun penelitian terdahulu yang ditulis oleh Weerasinghe, (2018)membahas mengenai pengaruh konten pemasaran terhadap customer online engagement. Hasilnya adalah bahwa konten pemasaran yang bisa berupa video, studi kasus, blog, infografik, meme dan foto, memiliki pengaruh yang positif terhadap customer online engagement. Pada makalah ini didapatkan hasil bahwa gambar ataupun foto yang merupakan konten visual pada media sosial Instagram dapat membuat online engagement yang baik walaupun dimasa sulit saat terjadi pandemi.

\section{Media Sosial}

Media sosial didefinisikan sebagai kelompok aplikasi berbasis internet yang dibangun atas ideologi dan teknologi web 2.0 yang memungkinkan pembuatan dan pertukaran konten buatan pengguna (Mahoney \& Tang, 2016), sehingga media ini kerap digunakan untuk menghubungkan seseorang dengan orang lainnya, menjadi tempat untuk saling berinteraksi, membangun kepercayaan, bahkan juga menjadi media untuk menawarkan dan menjual suatu barang atau produk (Safko \& Brake, 2009). Menurut Lipschultz (2017), media sosial dapat dibedakan dari berapa tinggi tingkat interaktivitas antar penggunanya, seberapa penting formasi identitas pengguna dan keterbukaan untuk berbagi konten di seluruh komunitas yang sedang berkembang.

Salah satu peran media sosial saat ini adalah membantu para pelaku bisnis untuk memasarkan dan menjual produknya. Media Sosial menawarkan lebih 
banyak kemungkinan bagi pemasar untuk terlibat dan berinteraksi dengan pelanggan daripada pemasaran tradisional (Gros, 2012, dikutip dalam Ahmed \& Zahid, 2014).

Banyak sekali media sosial yang ada salah satunya Instagram. Instagram merupakan salah satu terobosan media sosial dari revolusi iPhone. Pada Agustus 2012, Instagram mampu mengalahkan Twitter dari segi pengguna aktif sehari-hari (Miles, 2014). Media sosial ini memberikan layanan untuk berbagi gambar atau foto yang disertai caption juga video.

\section{Konten Visual}

Konten visual merupakan berbagai bentuk konten atau isi yang dapat dinikmati secara visual dalam sebuah media di dunia teknologi yang ada pada saat ini baik itu berupa foto, ilustrasi atau video (Martajaya \& Sari, 2021). Konten visual dapat menarik perhatian target market untuk melihat konten yang ditawarkan, dengan 90\% informasi ditransmisikan ke otak melalui penglihatan (Saputra et al., 2020).

Perusahaan-perusahaan kerap menggunakan konten visual sebagai alat yang penting dalam membangun, membentuk dan merencanakan berbagai agenda guna mencapai tujuan tertentu (Kiousis el at., 2007 dalam Lock \& Araujo, 2020). Lebih jauh lagi, bahwa konten visual ini tidak hanya penting untuk menarik perhatian, tetapi juga dapat memberikan efek yang lebih spesifik, seperti mampu membantu target market dalam memahami konten lebih baik, membangkitkan emosi (Smith-Rodden \& Ash, 2012 dalam Lock \& Araujo, 2020) serta mengingkatkan memori dan membantu mengingat suatu informasi (de Haan et al., 2018 dalam Lock \& Araujo, 2020). 


\section{Online Engagement}

Online engagement merupakan engagement atau keterikatan dan keterlibatan konsumen pada media online yang meliputi aktivitas mereka dengan media tersebut (Zyminkowska, 2019). Indikator online engagement dapat diukur yakni reaksi terhadap konten (like), komentar pada suatu konten (comment), berbagi konten (share), dan mengunggah suatu konten (upload) (Rohadian \& Amir, 2019).

Media sosial yang baik tidak hanya dilihat dari jumlah followers yang banyak namun juga dari engagement. Intensitas engagement menggambarkan adanya interaksi antar followers dengan media sosial tersebut. Bisa dikatakan media sosial memiliki engagement yang baik jika jumlah followers suatu akun adalah 500.000, maka setidaknya dalam setiap post-nya mampu mendapatkan minimal 4000 likes dan 15 comments (Pendle, 2020).

\section{METODE PENELITIAN}

Jenis penelitian ini adalah deskriptif kualitatif, yakni suatu teknik yang menggambarkan dan menginterpretasikan data-data yang telah terkumpul dengan memberikan perhatian dan merekam sebanyak mungkin aspek situasi yang diteliti pada saat itu, sehingga memperoleh gambaran secara umum dan menyeluruh tentang keadaan sebenarnya (Kriyantono, 2014). Penelitian yang menggunakan metode deskriptif menuntut peneliti untuk dapat menganalisis data yang dikumpulkan berupa kata-kata, gambar dan bukan angka-angka (Moleong, 2017). Data yang didapatkan untuk diteliti merupakan konten visual dari Kopi Toko Djawa di Bandung yang merupakan salah satu kedai kopi yang sering disebut sebagai kedai kopi yang wajib dikunjungi. Pengumpulan data berasal dari wawancara, foto, dokumen pribadi, catatan atau memo dan dokumen resmi lainnya. 
Konten visual yang digunakan sebagai objek penelitian adalah gambar atau foto yang terdapat pada akun Instagram Kopi Toko Djawa selama pandemi, yakni konten visual dengan jumlah like terbanyak. Jumlah ini merupakan $10 \%$ dari jumlah konten visual yang dipublikasikan oleh Kopi Toko Djawa selama periode pandemi, yakni Maret - Juni 2020. Selain itu wawancara juga dilakukan dengan narasumber yang merupakan pengikut atau followers pada Instagram atau konsumen Kopi Toko Djawa. Wawancara dilakukan kepada 31 responden dengan menunjukkan lima konten visual sebagai bahan untuk menjawab pertanyaan. Lima konten visual tersebut merupakan bagian dan mewakili dari 12 konten dengan like terbanyak, karena dari 12 konten tersebut dilihat adanya kemiripan sehingga hanya ditemukan lima jenis konten visual yang berbeda. Untuk memperkuat hasil data, dilakukan juga penghitungan jumlah like dan comment menurut Pendle (2020) dimana engagement yang baik jika jumlah followers suatu akun adalah 500.000 mampu mendapatkan minimal 4000 likes dan 15 comments.

Fokus penelitian ini secara garis besar adalah menganalisis apakah konten visual pada akun Instagram Kopi Toko Djawa mampu membangun online engagement yang baik, diukur dari jumlah like dan comment yang merupakan respon dari tiga jenis konten visual Kopi Toko Djawa yakni fotografi murni, fotografi dengan tulisan dan ilustrasi vektor yang dipublikasikan pada akun Instagram Kopi Toko Djawa pada periode Maret - Juni 2020.

\section{HASIL DAN DISKUSI}

Penelitian ini membahas bagaimana konten visual dan kaitannya pada online engagement para follower Instagram Kopi Toko Djawa di masa pandemi. Gambar 1 adalah tampilan dari akun Instagram Kopi Toko Djawa. 


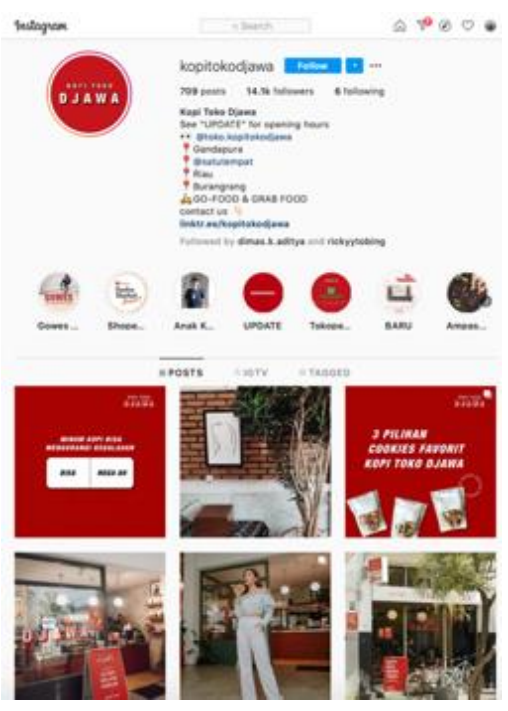

Gambar 1 Tampilan akun Instagram Kopi Toko Djawa Sumber: Instagram Kopi Toko Djawa (2020)

Visualisasi yang ditampilkan pada akun Instagram Kopi Toko Djawa memiliki tiga jenis yakni, fotografi murni, fotografi yang diolah dan diberi teks, dan ilustrasi vektor. Konten visual yang ada pada halaman utama atau feed Instagram Kopi Toko Djawa tidak seluruhnya merupakan hasil buatan pemilik juga crew dari Kopi Toko Djawa, tetapi mereka juga menggunakan konten visual dari pengguna lain yang menandai atau tag akun Instagram Kopi Toko Djawa yang dapat dilihat pada gambar 2.

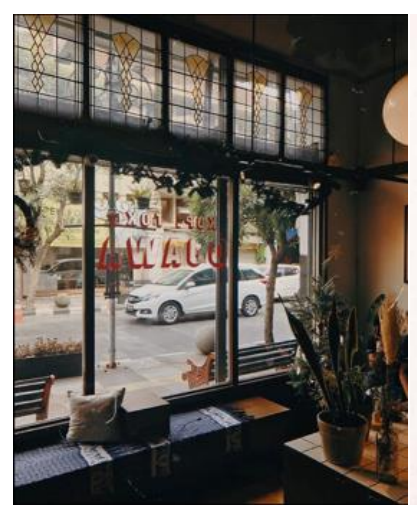

(a)

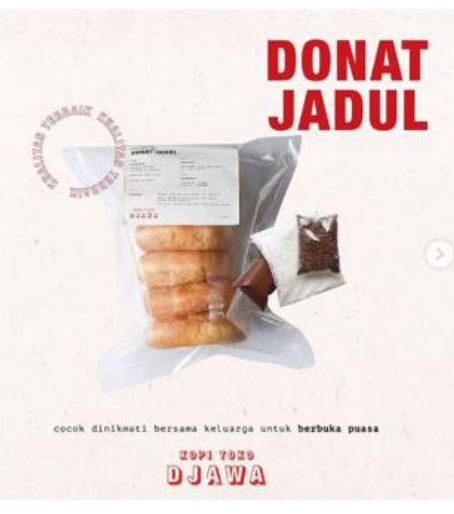

(b)

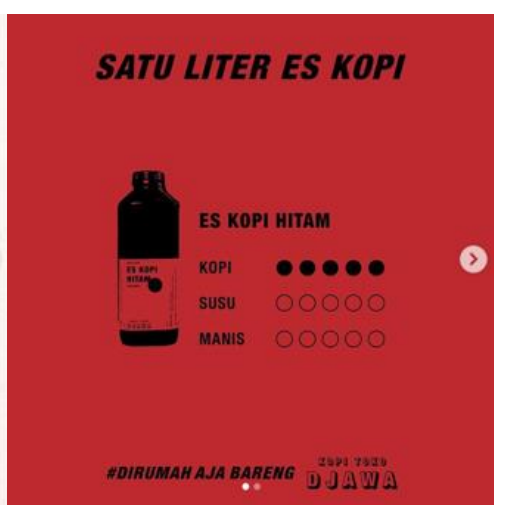

(c)

Gambar 2. Tiga jenis konten visual yakni, fotografi murni, fotografi dengan tulisan dan, ilustrasi vektor Sumber: Instagram Kopi Toko Djawa (2020) 
Rizki Yantami Arumsari, Yanuar Rahman dan Bijaksana Prabawa PAPARAN KONTEN VISUAL PADA FEED INSTAGRAM KOPI TOKO DJAWA SELAMA PANDEMI COVID-19,

\section{Karakteristik visual pada akun Instagram Kopi Toko Djawa selama pandemi}

Konten visual yang ditampilkan pada akun Instagram Kopi Toko Djawa selalu mendapatkan like dan comment atau komentar dalam jumlah yang berbeda-beda, dapat dilihat pada tabel 1.

Tabel 1 Konten visual terpilih pada akun Instagram Kopi Toko Djawa

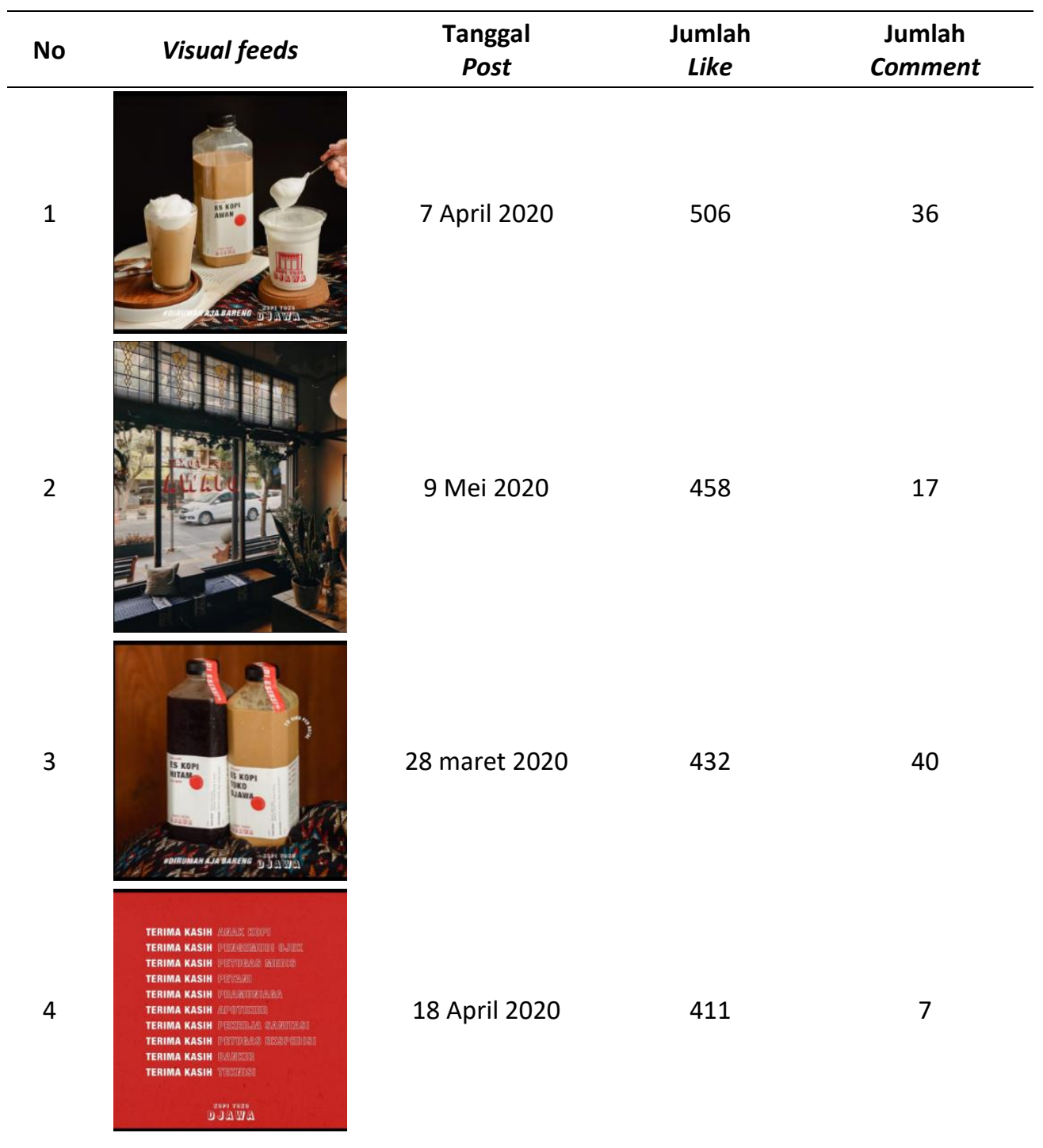




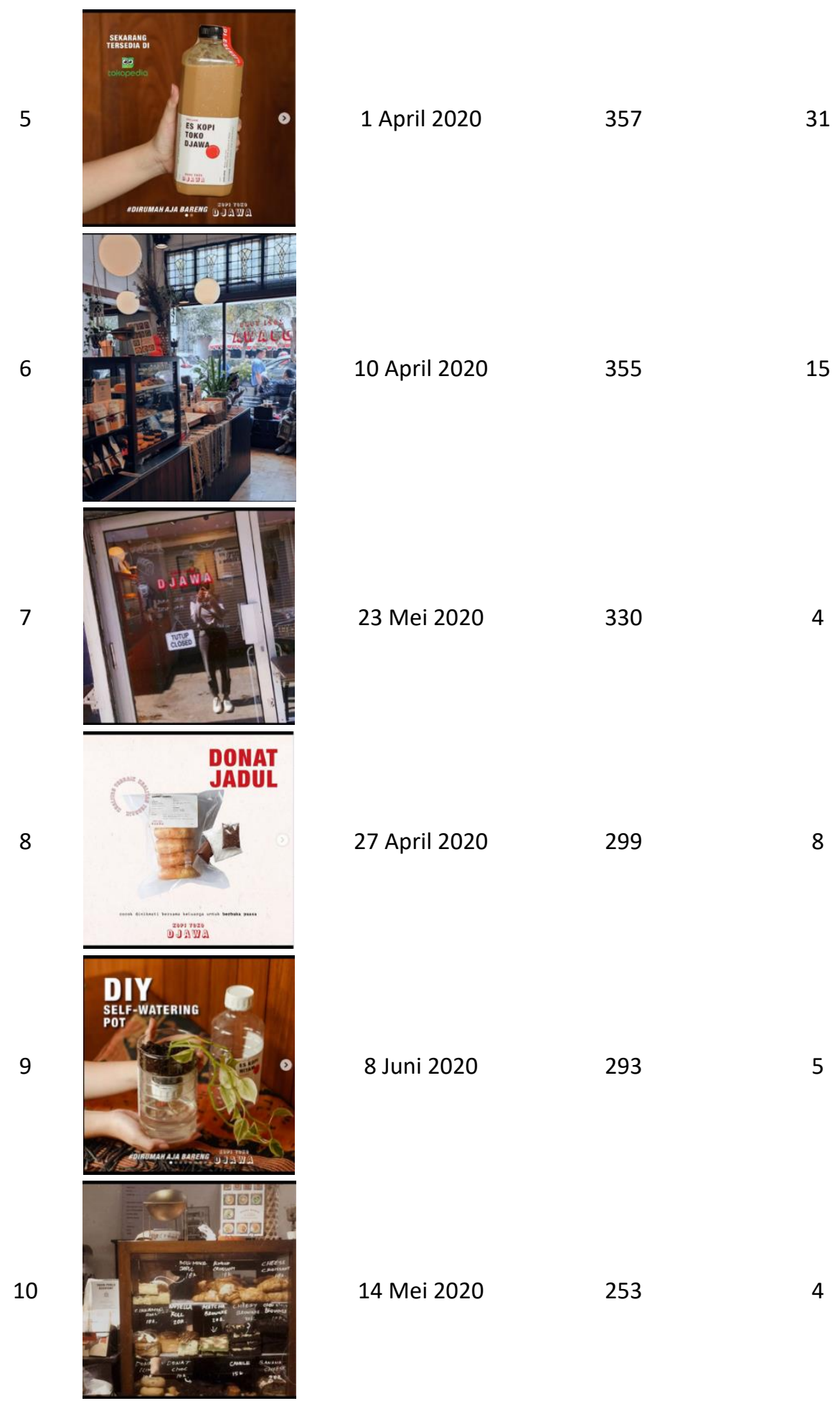


Rizki Yantami Arumsari, Yanuar Rahman dan Bijaksana Prabawa PAPARAN KONTEN VISUAL PADA FEED INSTAGRAM KOPI TOKO DJAWA SELAMA PANDEMI COVID-19,

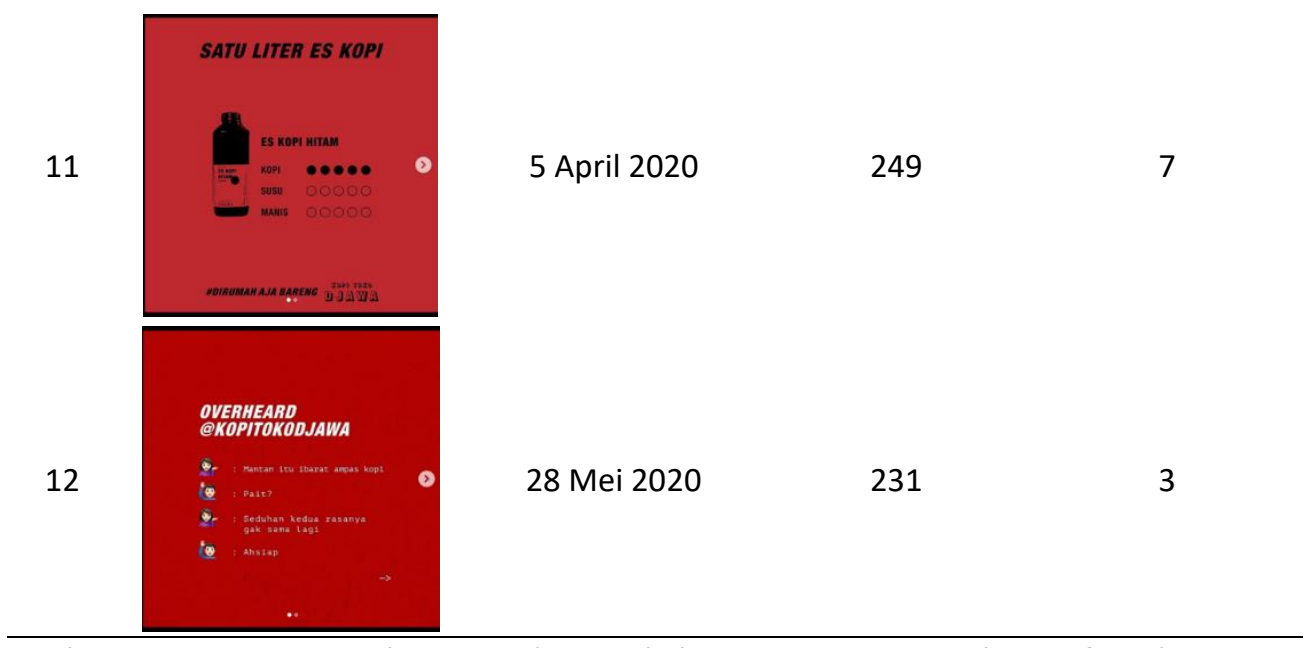

Sumber: Instagram Kopi Toko Djawa dan Hasil observasi Arumsari, Rahman, \& Prabawa

(2020)

Pada tabel 1, terdapat satu post yang dibuat oleh Kopi Toko Djawa bertemakan COVID-19, yakni pada nomor 4 dengan jenis ilustrasi vektor yang berbunyi ucapan terima kasih kepada para pekerja yang berada di garda terdepan. Sedangkan 11 konten visual lainnya tidak mengangkat tema COVID-19 dan hanya mempromosikan produk mereka.

Jenis konten visual yang mendapat like terbanyak berjumlah 506 adalah konten visual yang berjenis fotografi dengan sedikit teks, visualisasi ini lebih menunjukkan dominasi fotografis yang mengekspos produk kopi dari Toko Kopi Djawa. Konten ini mendapat like banyak dikarenakan sifatnya yang persuasif terlebih dengan pemilihan objek yang didukung dengan deskripsi teks/ caption yang sesuai (Nurusholih, 2019). Konten visual dengan jenis ilustrasi vektor juga cukup mendapat jumlah like yang relatif banyak seperti konten visual ucapan terima kasih kepada para pekerja garda terdepan. Lain halnya dengan konten visual dengan jenis ilustrasi vektor yang bertema promosi produk, justru hanya mendapat jumlah like dibawah 250.

Aspek comment atau komentar juga mengindikasikan peranan penting dalam sebuah online engagement pada media sosial. Konten visual dengan jumlah 
komentar terbanyak yakni 40, adalah konten visual berjenis fotografi dengan sedikit teks. Konten tersebut mendapatkan komentar terbanyak karena menginformasikan adanya produk baru, harga, dan tautan untuk memesannya. Para follower juga memberikan komentar yang bermacam-macam, ada yang antusias, ada yang mempertanyakan ketahanan produknya, ada yang membandingkan harga, dan lain sebagainya.

Konten visual yang memiliki jumlah like terbanyak, mendapat jumlah komentar sebanyak 36, jumlah tersebut hanya berbeda empat komentar dengan konten visual urutan ketiga namun memiliki jumlah komentar terbanyak. Informasi yang diberikan pada deskripsi dari konten visual tersebut sama, yakni memberi informasi mengenai produk baru namun hanya sekedar inovasi produk dan di mana pelanggan bisa mendapatkannya. Komentar yang diberikan oleh pengikut Instagram Kopi Toko Djawa berada pada bahasan tentang harga, ketahanan produk, dan cara penyimpanan.

\section{Akun Instagram Kopi Toko Djawa dalam membangun online engagement selama pandemi}

Setelah melakukan observasi visual, peneliti juga melakukan wawancara kepada 31 responden. Adapun rangkuman hasil wawancara tersebut adalah:

Tabel 2 Rangkuman hasil wawancara dengan konsumen

\begin{tabular}{ll}
\hline No & \multicolumn{1}{c}{ Kesimpulan Wawancara } \\
\hline 1 & 18 informan memberi like pada konten visual Kopi Toko Djawa karena konten yang mereka \\
& hadirkan memiliki visual yang menarik. Mereka memberi like karena deskripsi foto yang \\
& menarik, adanya promo, adanya produk baru, dan foto yang memperlihatkan suasana kafe, \\
& juga produk yang terlihat pada konten visual sangat menggugah selera. Terdapat juga \\
& informan yang tidak pernah memberi like karena tanpa melihat konten visual pun dia sudah \\
& menjadi konsumen setia Kopi Toko Djawa. \\
2 & $\begin{array}{l}29 \text { informan tidak pernah memberikan comment apapun di kolom komentar namun ada } \\
\text { satu informan yang pernah memberikan comment. }\end{array}$
\end{tabular}


316 informan merasa tertarik dengan konten visual yang dihadirkan oleh Kopi Toko Djawa selama pandemi walaupun ada informan yang memberikan saran agar visual dibuat bervariasi.

4 Menurut para informan, visual yang menarik menjadi hal penting agar para follower atau siapapun yang melihat konten tersebut dapat memberikan like.

5 Konten visual yang konsisten sangat dibutuhkan untuk menarik pelanggan baru dan juga sebagai identitas toko.

6 Dari lima visual yang ditampilkan saat wawancara, 17 informan berpendapat bahwa visual dengan fotografi murni dengan tulisan lebih menarik dibandingkan dengan empat visual lainnya. Alasannya karena fokus pada produk, lebih menggambarkan produk, estetik, lebih menggoda untuk mencoba produknya, dan penyajian yang berbeda.

Sumber : Data olahan Arumsari, Rahman, \& Prabawa (2020)

Hasil kesimpulan wawancara pada tabel 2, menunjukkan bahwa responden memberikan penilaian yang positif pada konten visual di akun Instagram Kopi Toko Djawa. Mereka sepakat bahwa konten visual harus dibuat dengan baik, konsisten, dan menampilkan produk yang nyata agar dapat menarik pelanggan, begitupun untuk mendapatkan like dari para pengikutnya. Selain itu, adanya promo menjadi hal yang menarik selama pandemi ini.

Jika dikaitkan dengan paparan Pendle (2020), media sosial dikatakan memiliki online engagement baik jika terdapat jumlah follower sebanyak 500.000 akun dan mampu mendapatkan minimal 4000 likes dan 15 comments. Bisa dihitung berarti persentasenya adalah 0,8\% dari follower, dan jumlah comment adalah 0,003\% dari follower. Berdasarkan teori tersebut dapat dihitung bahwa jumlah follower Instagram Kopi Toko Djawa sampai Juni 2020 sebanyak 14.100. Konten visual dengan like terbanyak selama pandemi yakni 506 dengan 36 comment. Berarti untuk jumlah like, $14.100 \times 0,8 \%=112,8$ atau 113. Sedangkan untuk comment, $14.100 \times 0,003 \%=0,423$ atau dibulatkan menjadi 1 comment Namun pada faktanya, konten visual tersebut mendapatkan jumlah like dan comment lebih dari hasil perhitungan, berarti online engagement pelanggan terhadap Instagram Kopi Toko Djawa berada pada kondisi yang baik. Hal tersebut membuktikan bahwa penelitian ini sejalan dengan penelitian tentang dampak 
content marketing terhadap customer online engagement (Weerasinghe, 2018) yang menyimpulkan bahwa konten visual memiliki pengaruh terhadap online engagement. Sehingga dapat dikatakan bahwa membuat konten visual yang baik dan konsisten dapat menciptakan online engagement yang baik dengan para pengikut akun Instagramnya.

\section{KESIMPULAN}

Dari hasil penelitian yang telah dilakukan, Instagram Kopi Toko Djawa sudah memiliki online engagement yang bagus dengan konsumen atau follower selama pandemi (Maret - Juni 2020). Hal tersebut dibuktikan dengan jumlah like dan comment yang merupakan respon dari tiga jenis konten visual Instagram Kopi Toko Djawa yakni fotografi murni, fotografi dengan tulisan dan ilustrasi vektor yang melebihi batas persentase seharusnya. Selain itu juga, dengan adanya promosi dan produk baru yang dibuat oleh Kopi Toko Djawa membuat online engagement dengan follower dan konsumennya tetap baik.

Dapat dikatakan, pada masa pandemi yang sulit, pebisnis tetap bisa mendapatkan atau mempertahankan konsumen dengan membangun online engagement yang baik melalui konten visual yang menarik dan dipublikasikan secara konsisten.

Penelitian ini masih terbatas menganalisis jumlah like dan comment dari konten visual Instagram Kopi Toko Djawa sehingga saran untuk peneliti berikutnya adalah dapat menganalisis mengenai kriteria online engagement lainnya seperti share dan save agar dapat dijadikan acuan bagi para pebisnis untuk mengelola akun media sosialnya dengan menghadirkan konten visual yang baik untuk membangun online engagement yang lebih baik. 


\section{DAFTAR PUSTAKA}

Elvira, V. (2020, April 7). Merugi Akibat Corona, Sejumlah Kedai Kopi di Bandung Tutup Sementara. www.ayobandung.com https://ayobandung.com/read/2020/04/07/85207/merugi-akibatcorona-sejumlah-kedai-kopi-di-bandung-tutup-sementara

Ahmed, M. A., \& Zahid, Z. (2014). Role of Social Media Marketing to Enhance CRM and Brand Equity in Terms of Purchase Intention. ASIAN JOURNAL OF MANAGEMENT RESEARCH, 4(3), 533-549.

Ersoy, M. (2019). Social Media and Children. In Ş. Balcı \& Y. D. Birincioğlu (Eds.), Handbook of Research on Children's Consumption of Digital Media (pp. 11-23). IGI Global. https://doi.org/10.4018/978-1-52255733-3.ch002

Kriyantono, R. (2014). Teknik Praktis Riset komunikasi. Prenada Media. Kurniawati, W. D. N. (2016). Pemanfaatan Instagram Oleh Komunitas Wisata Grobogan Dalam Mempromosikan Potensi Pariwisata Daerah. Komuniti : Jurnal Komunikasi Dan Teknologi Informasi, VIII(2), 127-143. https://doi.org/10.23917/komuniti.v8i5.2943

Lipschultz, J. H. (2017). Social Media Communication: Concepts, Practices, Data, Law and Ethics (2nd ed., Issue). Routledge. https://doi.org/https://doi.org/10.4324/9781315388144

Lock, I., \& Araujo, T. (2020). Visualizing the triple bottom line: A largescale automated visual content analysis of European corporations' website and social media images. Corporate Social Responsibility and Environmental Management, 27(6), 2631-2641. https://doi.org/10.1002/csr.1988

Mahoney, L. M., \& Tang, T. (2016). Strategic Social Media From Marketing To Social Change. In Strategic Social Media. 
Martajaya, I. G. A. I. V., \& Sari, K. I. K. (2021). Analisis Virtual Maps dalam Pengembangan Pariwisata Denpasar di Era Revolusi 5.0. SANDI: Seminar Nasional Desain, 1, 208-214.

Miles, J. (2014). Instagram Power - Build Your Brand and Reach More Customers with the Power of Pictures. In Success Book Reviews.

Moleong, L. J. (2017). Metodologi Penelitian Kualitatif. In Kualitalif Sasial (37th ed.). Remaja Rosdakarya.

Nurusholih, S. (2019). Analisis Retorika Visual Konten Iklan Produk Pada Account Instagram Bank BNI. Desain Komunikasi Visual, Manajemen Desain Dan Periklanan (Demandia), 4(2), 199-214. https://doi.org/10.25124/demandia.v4i2.1935

Pendle, A. (2020). Instagram Your Brand. Lulu.com.

Rathore, A. K., \& Ilavarasan, P. V. (2019). Social Media and Business Practices. In Advanced Methodologies and Technologies in Media and Communications (pp. 522-538). IGI Global. https://doi.org/10.4018/978-1-5225-7601-3.ch042

Rohadian, S., \& Amir, M. T. (2019). Upaya Membangun Customer Engagement Melalui Media Sosial Instagram (Studi kasus: online shop yang menjual produknya sendiri). Journal of Entrepreneurship, Management, and Industry (JEMI), 2(4), 179-186.

Safko, L., \& Brake, D. K. (2009). Social Media Bible: Tactics, Tools \& Strategies for Business Success. In John Wiley \& Sons, Inc., Hoboken, New Jersey.

Saputra, D. H., Sutiksno, D. U., Kusuma, A. H. P., Romindo, Wahyuni, D., Purnomo, A., \& Simarmata, J. (2020). Digital Marketing: Komunikasi Bisnis Menjadi Lebih Mudah. Yayasan Kita Menulis. 
Weerasinghe, K. D. R. (2018). Impact of Content Marketing Towards the Customer Online Engagement. International Journal of Research in Business, Economics and Management, 2(3), 217-224.

Zyminkowska, K. (2019). Customer Engagement in Theory and Practice: A Marketing Management Perspective (1st ed.). Palgrave Pivot. https://doi.org/10.1007/978-3-030-11677-4 
Demandia, Vol. 06 No. 02 (September 2021)

Halaman ini sengaja dikosongkan 